\title{
Machinability study of Al-TiC metal matrix composite
}

\author{
Siddappa P. N. ${ }^{1^{*}}$, B. P. Shivakumar ${ }^{1}$, Yogesha K. B. ${ }^{1}$, Mruthunjaya M. ${ }^{1}$ and \\ Hanamantraygouda M. B. ${ }^{2}$ \\ ${ }^{1}$ Department of Mechanical Engineering, JSS Academy of Technical Education, Bengaluru-560060, \\ India, \\ ${ }^{2}$ Department of Mechanical Engineering, Sir M. Visvesvaraya Institute of Technology, Bengaluru- \\ 560057, India
}

\begin{abstract}
Aluminum Metal Matrix Composites have emerged as an advanced class of structural materials have a combination of different, superior properties compared to an unreinforced matrix, which can result in a number of service benefits such as increased strength, higher elastic moduli, higher service temperature, low CTE, improved wear resistance, high toughness, etc. The excellent mechanical properties of these materials together with weight saving makes them very attractive for a variety of engineering applications in aerospace, automotive, electronic industries, etc. Hence, these materials provide as alternative substitutes for conventional engineering materials when specific mechanical properties necessary for required applications. In this work an attempt is made to study the machining parameters of Al6061/TiC MMC. The composite is developed by reinforcing $\mathrm{TiC}$ particles in varying proportions of 3, 6, 9 and $12 \%$ weight fractions to the Al6061 matric alloy through stir casting technique. Cutting forces were measured by varying cutting speed and feed rate with constant depth of cut for different $\%$ weight fractions. The results showed that the cutting force increases with the increase of feed rate and decreases with the increase of cutting speed for all the weight fractions. Cutting parameters were optimized using Taguchi technique.
\end{abstract}

Keywords: Metal matrix composite; Weight fraction; Stir casting; Machinability.

\section{Introduction}

Machining is a secondary manufacturing process and it is described as an elimination of excess material from the metal component using power-driven machine. Machining of composites is more difficult and tedious task compared to conventional metals due to their complex nature. The composites require superior machining characteristics in terms of cutting tool material, tool geometry, tool design, cutting speed, feed, depth of cut, etc. Thus, in today's world, non-traditional methods of manufacturing or higher grades of cutting tools are preferred for the machining composites. Machinability can be compare in terms of tool life, cutting force, and surface finish under similar conditions. Tool life criterion is

\footnotetext{
${ }^{*}$ Corresponding author: siddappa.pn@gmail.com
} 
most important from the point of view of machining economics. Machinability rating of test material is given by $\mathrm{MR}=(\mathrm{V} 60 \mathrm{t} / \mathrm{V} 60 \mathrm{~s}) \times 100$. The specific cutting pressure and specific cutting power are often considered as index of machinability of the given work material. The larger the specific cutting energy, the smaller the machinability index.

\section{Literature review}

Composites have found application in many areas of daily life for quite some time and in engineering applications. Extensive development in the enhancement of composites have been achieve in recent days, so that they could be used for variety of applications. Pushpendra Kumar et al. [1] investigated on machining of Aluminum Metal Matrix Composites (AMMCs) by controlling the process parameters. The literature concluded that, by suitably selecting the machining parameters, AMMC could be machined economically. PCD tool is the most preferred. The process is still challenging due to non-homogenous and anisotropic nature of composites. V. Songemene et al. [2] studied machinability of aluminium alloy. The factors like cutting force, cutting speed, feed rate and chip formation were optimized while machining Al7075-T6. It was found that, thrust force is increases with feed rate at different cutting speeds. Cutting force is sensitive to the variation of feed and feed determines the chip thickness. Rabindra Behra et al. [3] conducted the machinability test on $\mathrm{SiC}$ reinforced $\mathrm{AMMC}$ by varying factors like cutting force, cutting speed, feed rate, cutting depth and surface finish. It was found that cutting force decreases with the increase of cutting speed. It was also noticed that cutting force increases with the increase of feed rate at constant depth of cut. It is found that at constant feed rate as the cutting speed increases, surface roughness decreases and the size of chip formation decreases with increasing weight fraction. Anand Kumar et al. [4] dealt with cutting parameters of Al-4.5\% Cu-TiC metal matrix composites using coated ceramic tools. Machining factors like cutting speed, cutting force and depth of cut were varied their effects on machining were studied. It is concluded that, tensile strength and hardness increases ductility reduces with the increase of wt.\% of TiC. Cutting force increased up to medium cutting speed of $80 \mathrm{~m} / \mathrm{min}$ and then decreased when cutting speed increased from medium to high speed $(120 \mathrm{~m} / \mathrm{min})$ wherein good surface finish was observed. Nassim Samer et al. [5] studied the microstructure and mechanical properties of Al-TiC metal matrix composite by reactive synthesis method. Aluminium composite prepared by nanometre sized TiC particles. The study concluded that, the composite Al-TiC MMC showed enhancing mechanical properties for a high volume fraction of reinforcement. The distribution of reinforcement particles was attribute to reactive synthesis route. Himanshu Kala et al. [6] investigated on the mechanical properties of AMMC contain single and multiple reinforcements. Reinforcement of aluminium and its alloys with ceramic particles showed considerable increase in mechanical properties. Suraya Sulaiman et al. [7] observed the process of determining the mechanical properties of $\mathrm{Al}-11.8 \% \mathrm{Si} / \mathrm{TiCp}$ composite. The study revealed that, addition of reinforcement particles, considerably improves the value of axial tensile strength of the MMC. The result shows that hardness and tensile strength decreases after 10 wt. \% of TiC reinforcements. P. Dhanasekaran et al. [8] found the tensile and tear behaviour of $\mathrm{TiC}$ reinforced with $\mathrm{Al} 6063$ alloy and SEM witnessed the dispersal of particulates in metal matrix. It was observed that, by incorporating $\mathrm{TiC}$ particles into matrix, dry wear properties, hardness and fluidity was enhanced. The wear of composite specimen decreases with increase in reinforcement fraction, which improves hardness. Venkatesan et al. [9] did the comparative analysis of $\mathrm{Al} \mathrm{MMC}$ reinforced with $\mathrm{TiC}$ and TiB2 with different weight percentages. This literature also analysed the mechanical and wear characteristics. The study revealed that increasing the percentage of TiC directly increases the ultimate tensile strength, yield strength, elasticity of modulus and decreases 
the percentage of elongation. Increasing the percentage of titanium boride increases the tensile strength and co-efficient of friction.

\section{Experimental Work}

\subsection{Material properties of Matrix and reinforcement}

Table 1 gives the chemical composition of Al6061 matrix and Table 2 provides the details of material properties of both matrix and reinforcement at room temperature.

Table 1. Chemical composition of Al6061 alloy

\begin{tabular}{|c|c|c|c|c|c|c|c|c|c|}
\hline Elements & $\mathrm{Mg}$ & $\mathrm{Si}$ & $\mathrm{Fe}$ & $\mathrm{Cu}$ & $\mathrm{Ti}$ & $\mathrm{Cr}$ & $\mathrm{Zn}$ & $\mathrm{Mn}$ & $\mathrm{Al}$ \\
\hline Percentage & 1.50 & 0.90 & 0.70 & 0.40 & 0.15 & 0.35 & 0.25 & 0.20 & Balance \\
\hline
\end{tabular}

Table 2. Material properties of Al6061 alloy and TiC particles

\begin{tabular}{|l|l|l|}
\hline Properties & $\mathrm{Al} 6061$ & TiC \\
\hline Density & $2.7 \mathrm{~g} / \mathrm{cm} 3$ & $4.93 \mathrm{~g} / \mathrm{cm} 3$ \\
\hline Melting Point & $5800 \mathrm{C}$ & $31400 \mathrm{C}$ \\
\hline Modulus of Elasticity & $70-80 \mathrm{GPa}$ & $400 \mathrm{GPa}$ \\
\hline Hardness & $95-97 \mathrm{BHN}$ & $3400 \mathrm{VHN}$ \\
\hline Particle size & - & $18 \mu \mathrm{m}$ \\
\hline
\end{tabular}

\subsection{Composite preparation}

Preheated $\mathrm{TiC}$ particles were poured in to the molten $\mathrm{Al} 6061$ alloy at $800^{\circ} \mathrm{C}$ in the graphite crucible, which is placed in the induction furnace and stirred for 15 minutes in a rotating graphite stirrer at $350 \mathrm{rpm}$. Composite mixture was degassed using commercially available hexachlro ethane degassing tablet and then poured in to preheated metallic moulds as per AFS standards as shown in Fig. 1 for 3\%, 6\%, 9\% and 12\% weight fractions. The obtained casts were machined to the required size of $30 \mathrm{~mm}$ diameter and $300 \mathrm{~mm}$ length as shown in Fig. 2.
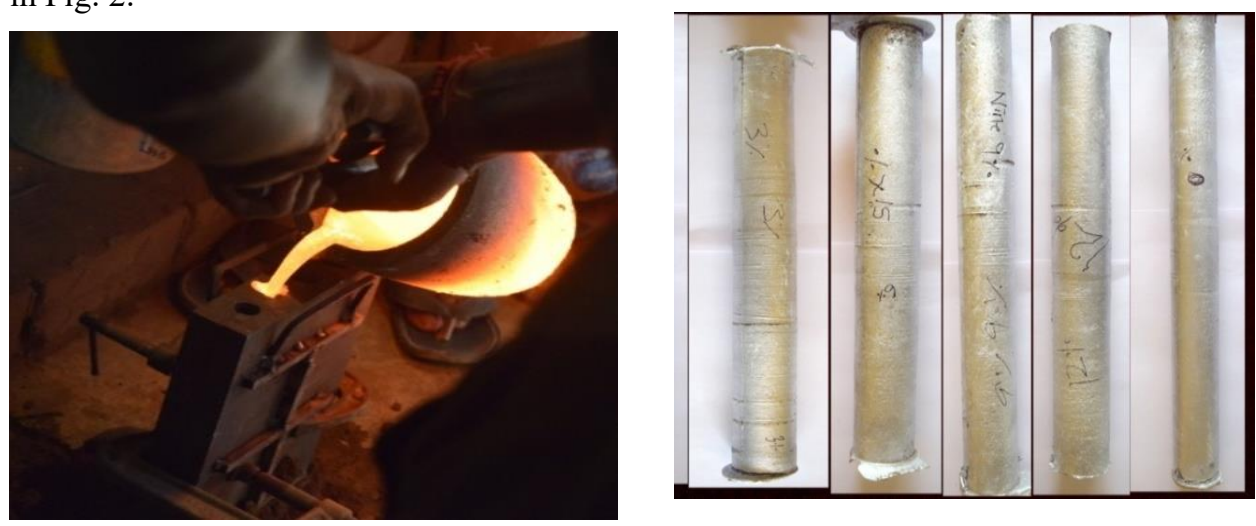

Fig.1. Pouring of molten metal in to the metal

Fig.2. Cast Specimens for different weight fractions mould 


\subsection{Experimental details}

Experiments were conducted on turning using turnmaster-35 lathe. IEICOS Model 621A lathe tool dynamometer was used to measure the cutting force, the details of lathe tool dynamometer is as shown in Table 3. In this study, three feed rates $0.2,0.28$ and 0.355 $\mathrm{mm} / \mathrm{rev}$. and three speeds $26.39,42.41$ and $66.91 \mathrm{~m} / \mathrm{min}$ is considered for the measurement of cutting force at constant depth of cut of $1 \mathrm{~mm}$ for different weight fractions. All the turning experiments were carried out in dry condition $[12,13]$.

Table 3. Specifications of lathe tool dynamometer

\begin{tabular}{|c|l|l|}
\hline $\begin{array}{c}\text { Sl. } \\
\text { No. }\end{array}$ & \multicolumn{1}{|c|}{ Specification } & \multicolumn{1}{c|}{ Values } \\
\hline 1 & Model & $621 \mathrm{~A}$ \\
\hline 2 & Range of force & $200 \mathrm{kgf}$ \\
\hline 3 & Directions & $\begin{array}{l}\mathrm{X}-\text { Horizontal; Y- } \\
\text { Vertical/Tangential; Z-Thrust }\end{array}$ \\
\hline 4 & Sensor type & Strain gauge \\
\hline 5 & Sensor resistance & $350 \Omega$ \\
\hline 6 & Bridge voltage & $8 \mathrm{~V}$ DC Max \\
\hline 7 & Operating temperature range & Ambient temperature \\
\hline
\end{tabular}

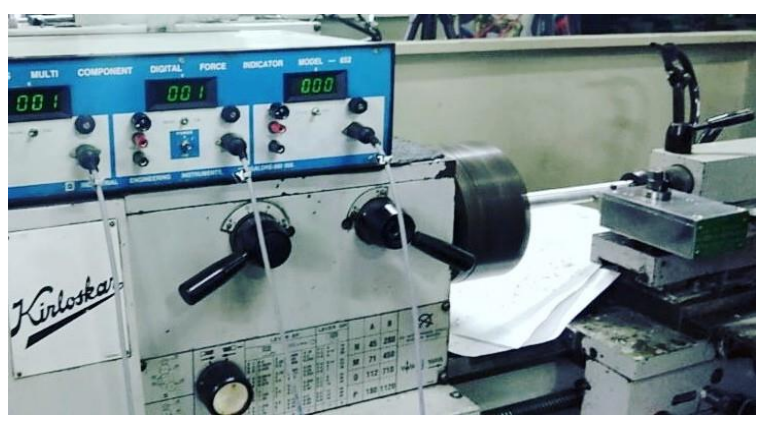

Fig.3. Experimental setup - Lathe and lathe tool dynamometer

\section{Results and Discussions}

\subsection{Microstructure study}

To ascertain the uniform distribution of reinforcement particles in the A16061 matrix alloy, microstructural study was carried for all the samples. SEM photographs were obtained for all the test specimens, which reveals that reinforcement particles are uniformly distributed throughout the composite material as shown in figures from 4 to 6 . Fig. 7 to 9 shows the EDX spectrums of the composite for 3\%,6\%, 9\% and 12\% weight fractions respectively. In all the spectrums it is observed that the presence of $\mathrm{TiC}$ particles along with other elements of Al6061 alloy [8]. 


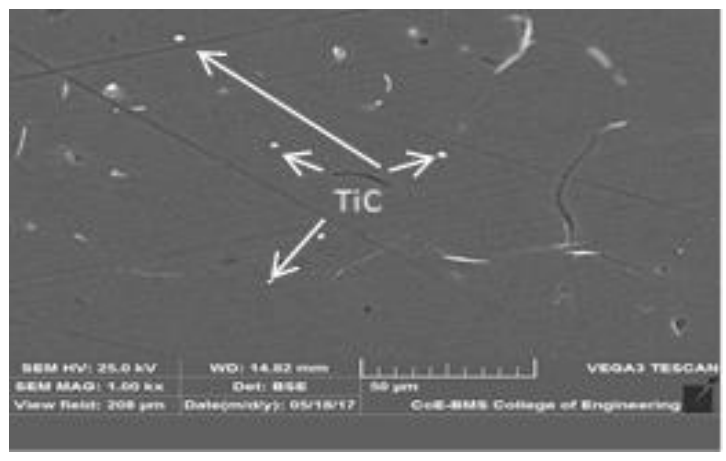

Fig. 4. SEM Micrograph depicting the presence of TiC particles in the composite for $3 \%$ reinforcement

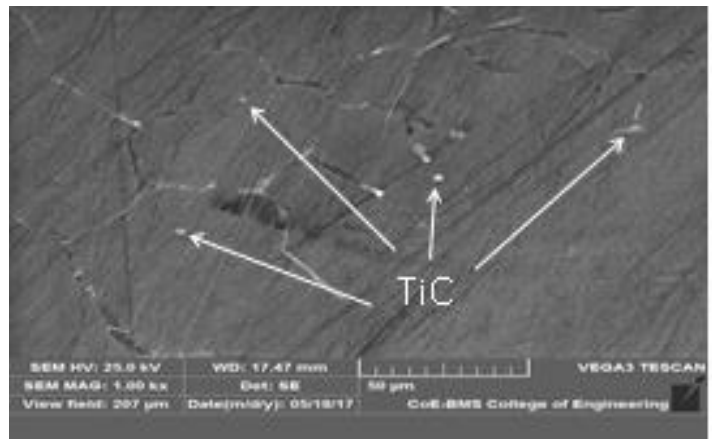

Fig. 5. SEM Micrograph depicting the presence of $\mathrm{TiC}$ particles in the composite for $6 \%$ reinforcement

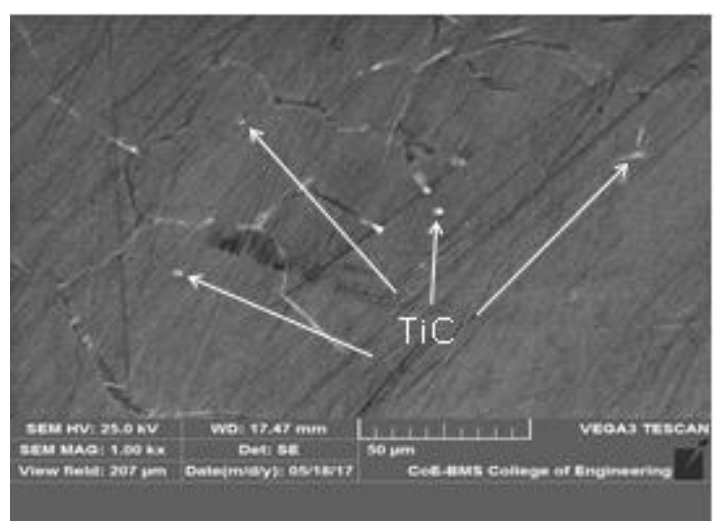

Fig. 6. SEM Micrograph depicting presence of TiC particles in the composite for $12 \%$ reinforcement 


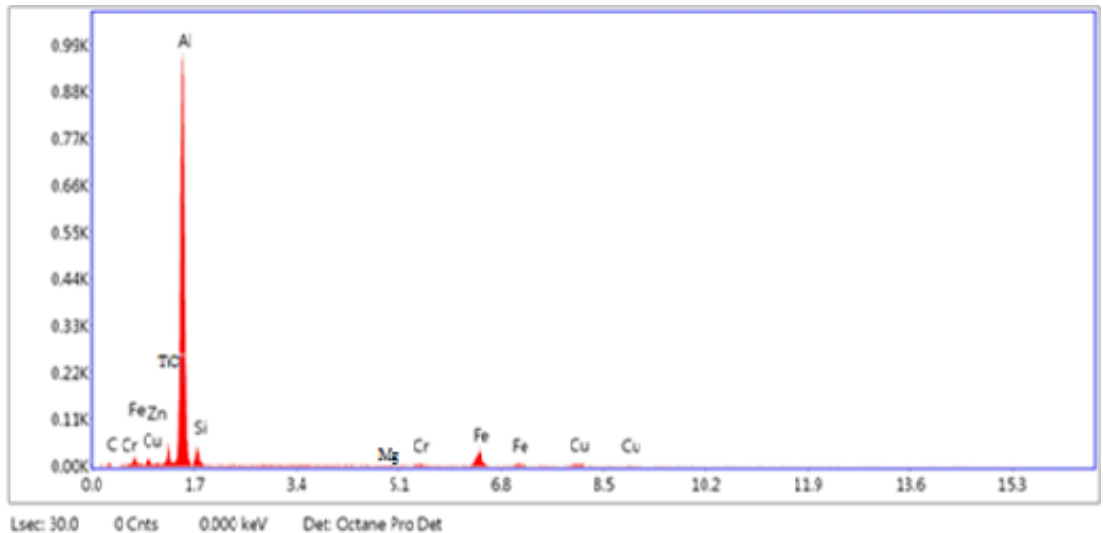

Fig. 7. EDX Pattern of Al-3\% TiC

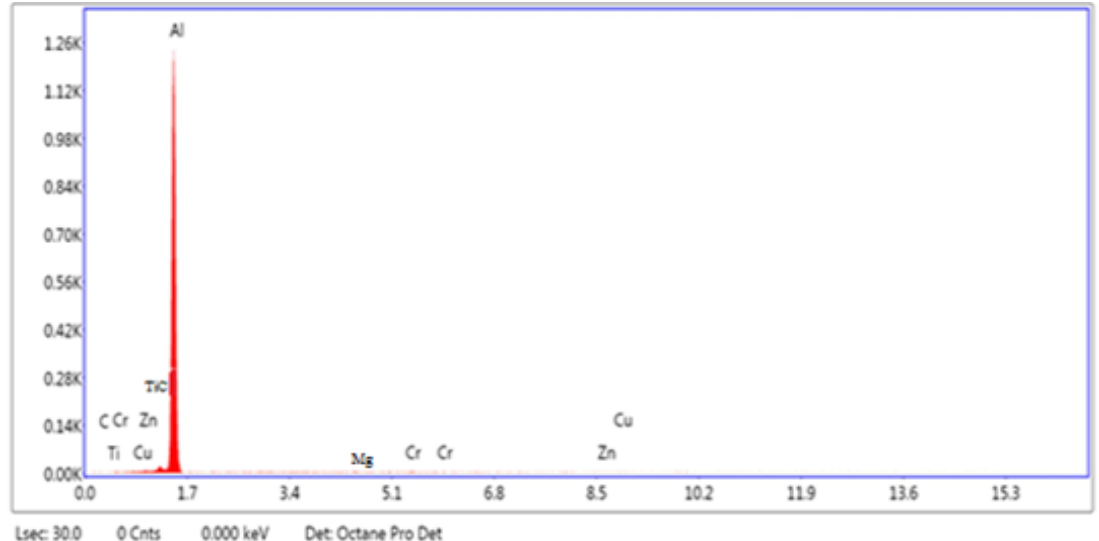

Fig. 8. EDX spectrum of Al6061/6 \% TiC MMC

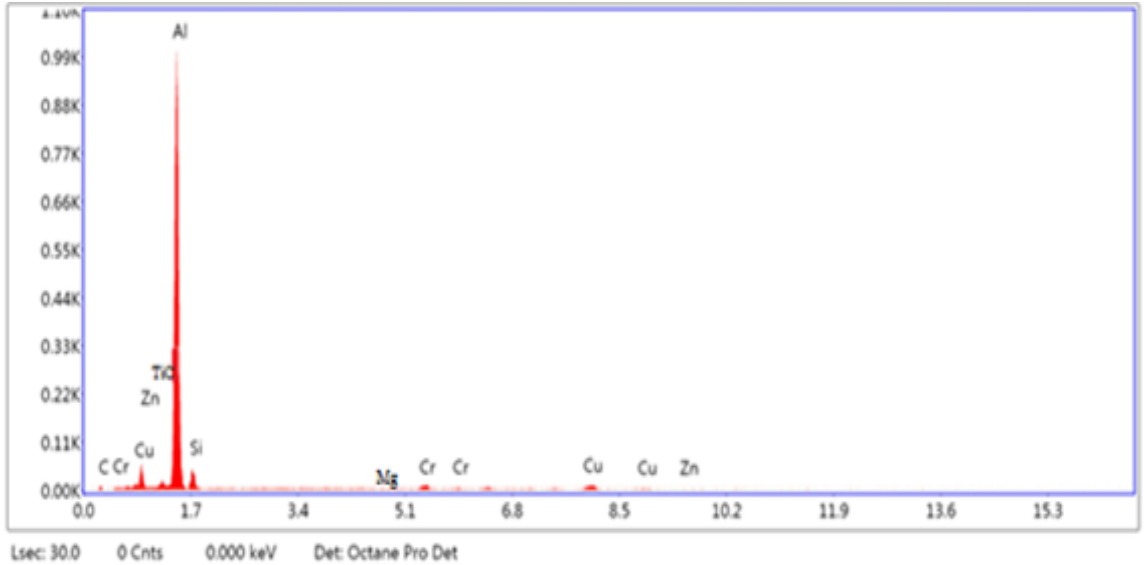

Fig. 9. EDX spectrum of Al6061/12 \% TiC MMC 


\subsection{Measurement of cutting force}

Machining of test specimens was carried out at a constant speed of $26.39 \mathrm{~m} / \mathrm{min}$ for three different feed rates, and cutting forces were measured for all the weight fractions. The same procedure was repeated for $42.41 \mathrm{~m} / \mathrm{min}$ and $66.91 \mathrm{~m} / \mathrm{min}$ speeds and the results were tabulated as shown in Table 4. The variation of measured cutting force against cutting speed and feed rates were plotted for all the weight fractions as shown in Fig. 10 to 15.

It is observed that, the cutting force increases with the increase of feed rate for all the constant speeds and also for all weight fractions. It is due to the increase of brittleness and also more friction between chip interfaces. In some cases, the cutting force decreases with the increase of feed rate, probably due to the delamination of TiC particles from the matrix and also due to slight reduction of brittleness of the composite because of increasing the temperature at higher feed rate. On the other hand, the cutting force decreases with the increase of cutting speed for all the constant feed rates and weight fractions, this may be due to reduction of friction at higher speeds [11].

Table 4. Cutting force values for different weight fractions

\begin{tabular}{|c|c|c|c|c|}
\hline $\begin{array}{l}\text { Trial } \\
\text { No. }\end{array}$ & $\begin{array}{c}\% \text { of } \mathrm{TiC} \\
\text { particles }\end{array}$ & $\begin{array}{c}\text { Cutting speed } \\
\mathrm{m} / \mathrm{min}\end{array}$ & $\begin{array}{l}\text { Feed rate } \\
(\mathrm{mm} / \mathrm{rev})\end{array}$ & $\begin{array}{c}\text { Cutting } \\
\text { force }(\mathrm{N})\end{array}$ \\
\hline 1 & \multirow{9}{*}{ particito } & \multirow{3}{*}{26.39} & 0.2 & 49 \\
\hline 2 & & & 0.28 & 88 \\
\hline 3 & & & 0.355 & 98 \\
\hline 4 & & \multirow{3}{*}{42.41} & 0.2 & 49 \\
\hline 5 & & & 0.28 & 59 \\
\hline 6 & & & 0.355 & 108 \\
\hline 7 & & \multirow{3}{*}{66.91} & 0.2 & 39 \\
\hline 8 & & & 0.28 & 98 \\
\hline 9 & & & 0.355 & 118 \\
\hline 1 & \multirow{9}{*}{3} & \multirow{3}{*}{26.39} & 0.2 & 59 \\
\hline 2 & & & 0.28 & 69 \\
\hline 3 & & & 0.355 & 78 \\
\hline 4 & & \multirow{3}{*}{42.41} & 0.2 & 39 \\
\hline 5 & & & 0.28 & 69 \\
\hline 6 & & & 0.355 & 98 \\
\hline 7 & & \multirow{3}{*}{66.91} & 0.2 & 59 \\
\hline 8 & & & 0.28 & 49 \\
\hline 9 & & & 0.355 & 118 \\
\hline 1 & \multirow{9}{*}{6} & \multirow{3}{*}{26.39} & 0.2 & 29 \\
\hline 2 & & & 0.28 & 118 \\
\hline 3 & & & 0.355 & 118 \\
\hline 4 & & \multirow{3}{*}{42.41} & 0.2 & 20 \\
\hline 5 & & & 0.28 & 20 \\
\hline 6 & & & 0.355 & 29 \\
\hline 7 & & \multirow{3}{*}{66.91} & 0.2 & 39 \\
\hline 8 & & & 0.28 & 49 \\
\hline 9 & & & 0.355 & 98 \\
\hline 1 & \multirow{8}{*}{9} & \multirow{3}{*}{26.39} & 0.2 & 59 \\
\hline 2 & & & 0.28 & 78 \\
\hline 3 & & & 0.355 & 118 \\
\hline 4 & & \multirow{3}{*}{42.41} & 0.2 & 78 \\
\hline 5 & & & 0.28 & 118 \\
\hline 6 & & & 0.355 & 137 \\
\hline 7 & & \multirow[b]{2}{*}{66.91} & 0.2 & 108 \\
\hline 8 & & & 0.28 & 118 \\
\hline
\end{tabular}




\begin{tabular}{|c|c|c|c|c|}
\hline 9 & & & 0.355 & 147 \\
\hline 1 & \multirow{9}{*}{12} & \multirow{3}{*}{26.39} & 0.2 & 69 \\
\hline 2 & & & 0.28 & 78 \\
\hline 3 & & & 0.355 & 78 \\
\hline 4 & & \multirow{3}{*}{42.41} & 0.2 & 49 \\
\hline 5 & & & 0.28 & 59 \\
\hline 6 & & & 0.355 & 128 \\
\hline 7 & & \multirow{3}{*}{66.91} & 0.2 & 78 \\
\hline 8 & & & 0.28 & 128 \\
\hline 9 & & & 0.355 & 137 \\
\hline
\end{tabular}

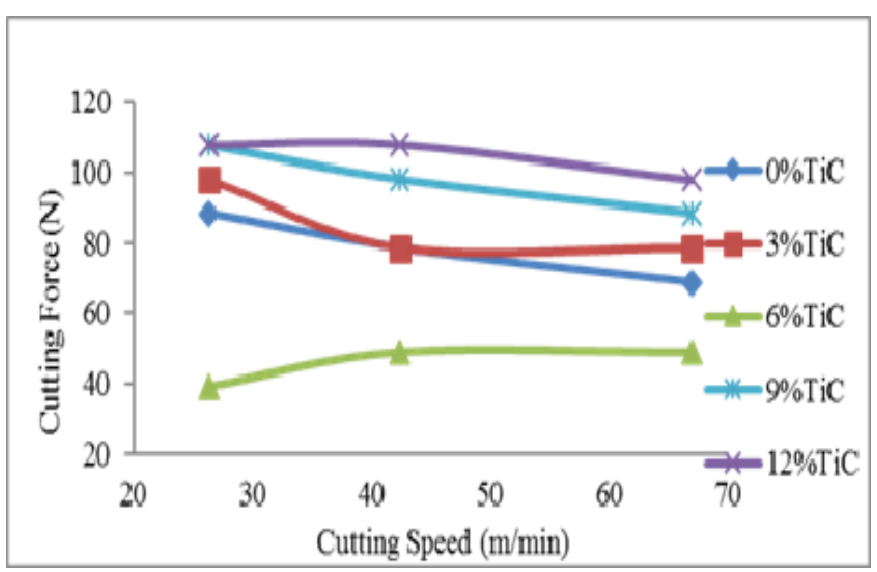

Fig. 10. Variation of cutting Force with the increase of cutting speed for different weight fractions at feed rate of $0.2 \mathrm{~mm} / \mathrm{rev} \& 1 \mathrm{~mm}$ depth of cut

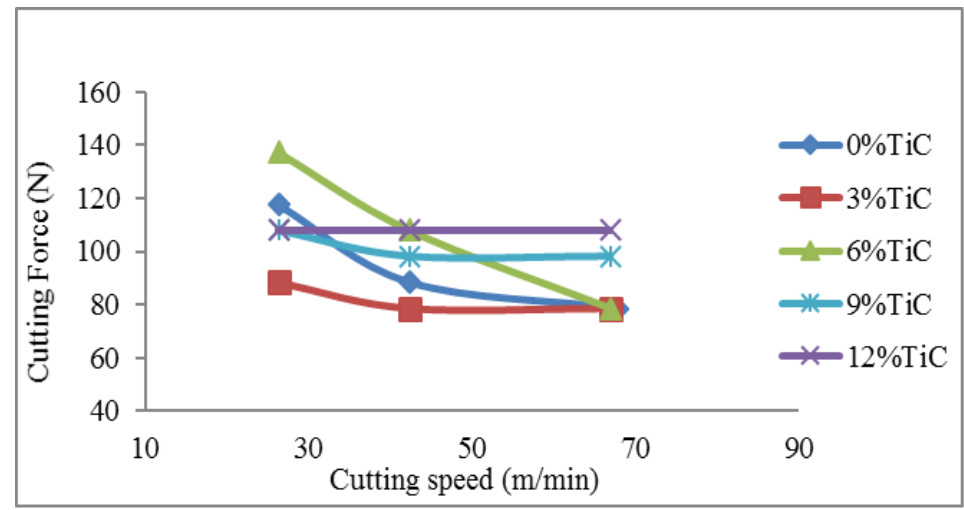

Fig. 11. Variation of cutting force with the increase of cutting speed for different weight fractions at feed rate of $0.28 \mathrm{~mm} / \mathrm{rev} \& 1 \mathrm{~mm}$ depth 


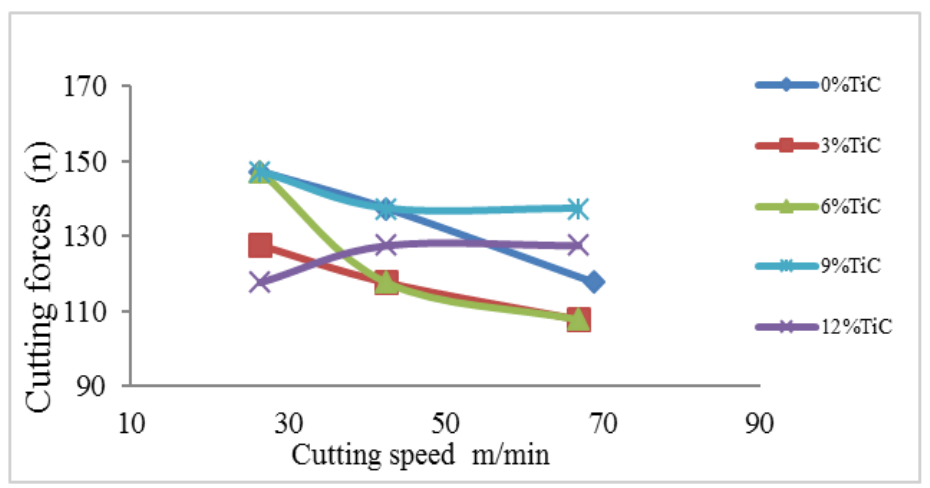

Fig. 12. Variation of cutting force with the increase of cutting speed for different weight fractions at feed rate of $0.355 \mathrm{~mm} / \mathrm{rev} \& 1 \mathrm{~mm}$ depth of cut

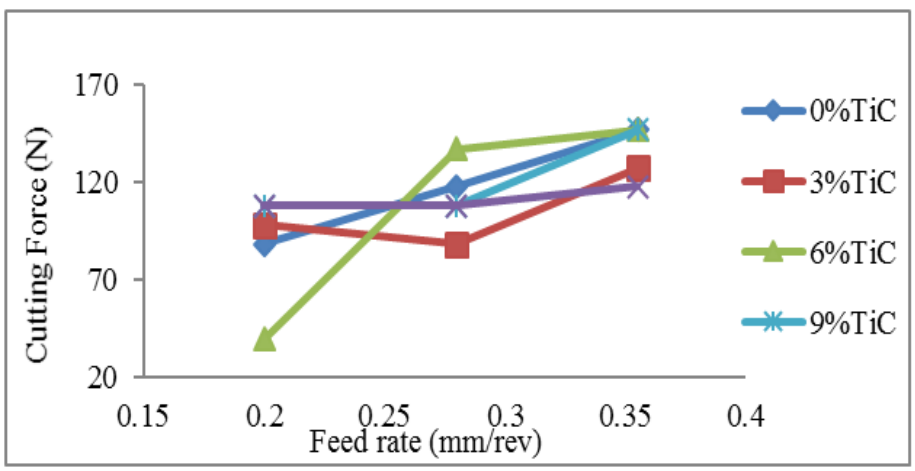

Fig. 13. Variation of cutting force with the increase of feed rate for different weight Fractions at constant speed of $26.4 \mathrm{~m} / \mathrm{min} \& 1 \mathrm{~mm}$ depth of cut

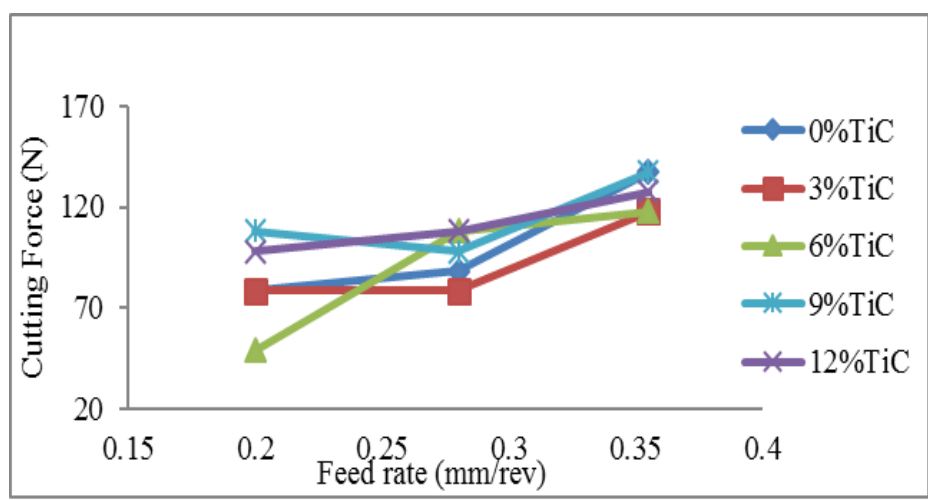

Fig. 14. Variation of cutting force with the increase of feed rate for different weight fractions at constant speed of $42.41 \mathrm{~m} / \mathrm{min} \& 1 \mathrm{~mm}$ depth of cut 


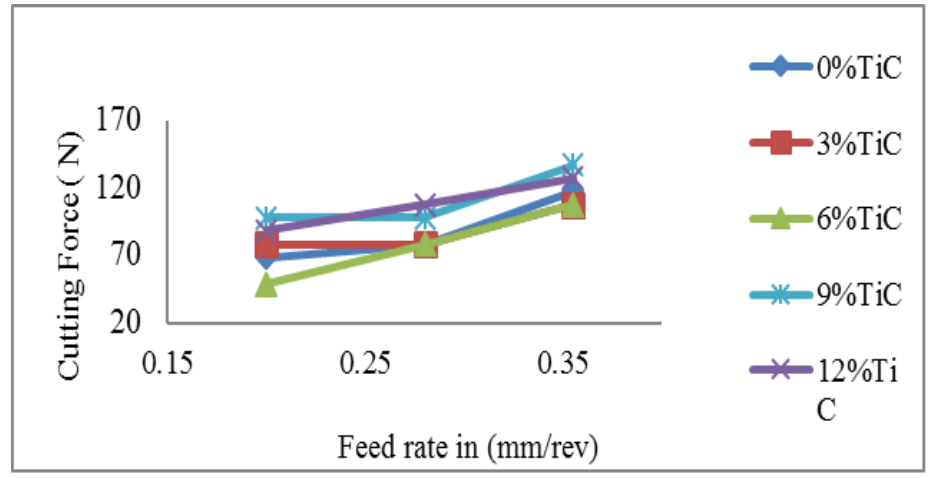

Fig. 15. Variation of cutting force with the increase of feed rate for different weight fractions at constant speed of $66.92 \mathrm{~m} / \mathrm{min} \& 1 \mathrm{~mm}$ depth of cut

\subsection{Hardness}

Hardness test was carried out on model $\mathrm{KB} 3000 \mathrm{H}$ Brinell hardness tester. Three trials were conducted for each composition, average values were calculated, and the results were tabulated as shown in Table 9. It is observed from that, hardness of the composite increases with the increase of wt.\% of $\mathrm{TiC}$ particles because of increasing the brittleness of the composite.

Table 5. Hardness test results

\begin{tabular}{|c|c|c|c|c|c|}
\hline $\begin{array}{c}\text { Sl. } \\
\text { No. }\end{array}$ & Material & $\begin{array}{c}\text { Force } \\
\text { applied in } \\
\mathrm{N}\end{array}$ & $\begin{array}{c}\text { Indentor } \\
\text { diameter, } \\
\text { in mm }\end{array}$ & $\begin{array}{c}\text { Indentation } \\
\text { diameter, } \\
\text { in mm }\end{array}$ & $\begin{array}{c}\text { Brinell } \\
\text { Hardness } \\
\text { Number } \\
\text { (BHN) }\end{array}$ \\
\hline 1 & $\mathrm{Al}-6061+0 \% \mathrm{TiC}$ & 500 & 10 & 3.7 & 44.88 \\
\hline 2 & $\mathrm{Al}-6061+3 \% \mathrm{TiC}$ & 500 & 10 & 3.6 & 47.46 \\
\hline 3 & $\mathrm{Al}-6061+6 \% \mathrm{TiC}$ & 500 & 10 & 3.5 & 50.31 \\
\hline 4 & $\mathrm{Al}-6061+9 \% \mathrm{TiC}$ & 500 & 10 & 3.3 & 56.81 \\
\hline 5 & $\mathrm{Al}-6061+12 \% \mathrm{TiC}$ & 500 & 10 & 3.1 & 64.60 \\
\hline
\end{tabular}

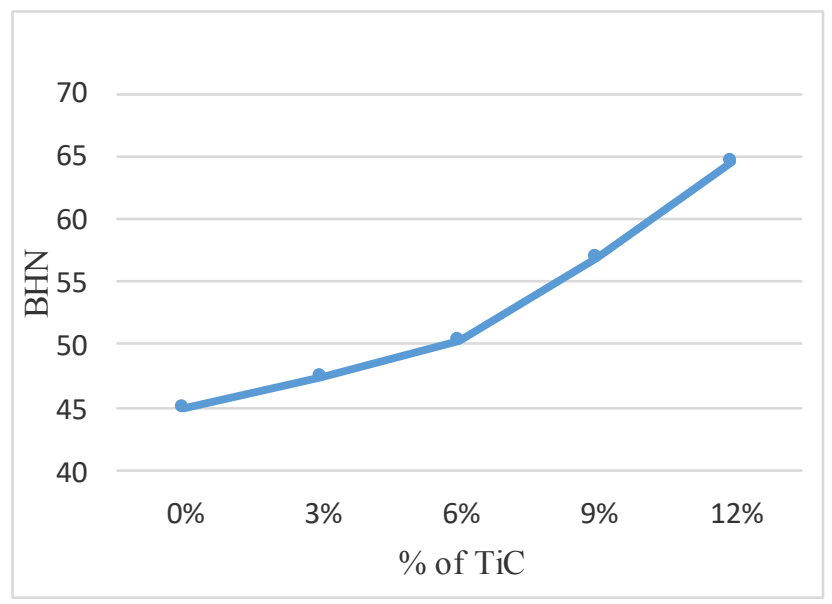

Fig. 16. Variation of hardness with the increase of reinforcement in the composite 


\subsection{Design of experiments (DOE)}

Taguchi technique was adopted to determine the best probable grouping of process parameters to compute minimum cutting force [11]. Taguchi techniques like orthogonal arrays and signal to noise $(\mathrm{S} / \mathrm{N})$ ratio are the major tools used for minimizing of machining parameters. Orthogonal array provide several design parameters instantaneously and design of experiments with array of orthogonal declares stable evaluation and interaction of design factors. The representations for the columns of the orthogonal array with experimental process factors were optimized and the rows represent the levels of each parameter.

Table 6. Process parameters and their levels

\begin{tabular}{|l|l|l|l|}
\hline Process parameter & Level 1 & Level 2 & Level 3 \\
\hline Cutting speed $(\mathrm{m} / \mathrm{min})$ & 26.39 & 42.41 & 66.91 \\
\hline Feed rate $(\mathrm{mm} / \mathrm{rev})$ & 0.2 & 0.28 & 0.355 \\
\hline Depth of cut $(\mathrm{mm})$ & 1 & 1 & 1 \\
\hline
\end{tabular}

$\mathrm{S} / \mathrm{N}$ ratio was calculated using Taguchi method in Minitab software (version: 17). The experiments were carried out using parameters of the L9 orthogonal array. Table 6 shows the experimental plan based on L9 orthogonal array.

\subsection{Analysis of S/N Ratio}

In the present study, minimum cutting force was considered as quality characteristic for turning of $\mathrm{Al}$ 6061/TiC MMC. Lower of cutting force is desirable, thus "Lower is better" concept was adopted for optimizing the process parameters using Taguchi technique.

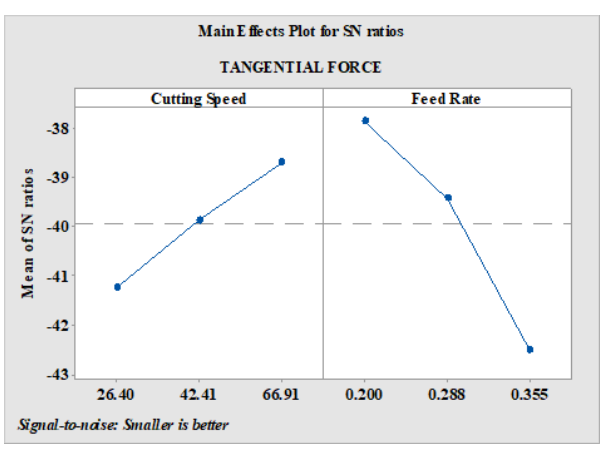

Fig. 16. Plots for SN ratio of Al6061- Alloy $\mathrm{TiC}$

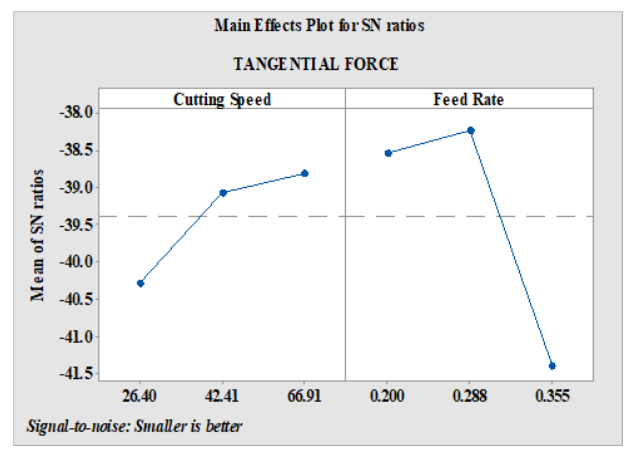

Fig. 17. Plots for SN ratio of Al-6061 with 3\% 

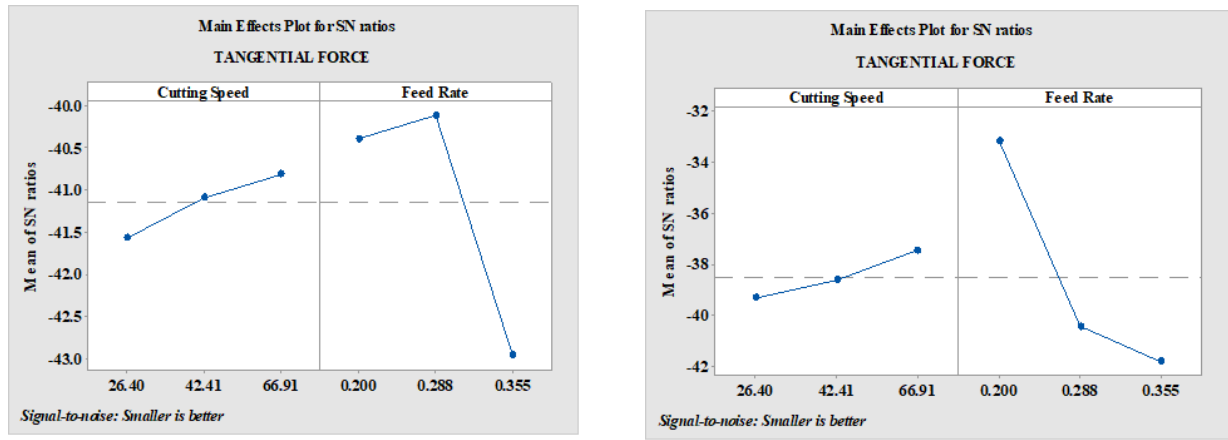

Fig. 18. Plots for $\mathrm{SN}$ ratio of $\mathrm{Al}-6061$ with $6 \% \mathrm{TiC}$ Fig. 19. Plots for $\mathrm{SN}$ ratio of Al-6061 with $9 \%$

$\mathrm{TiC}$

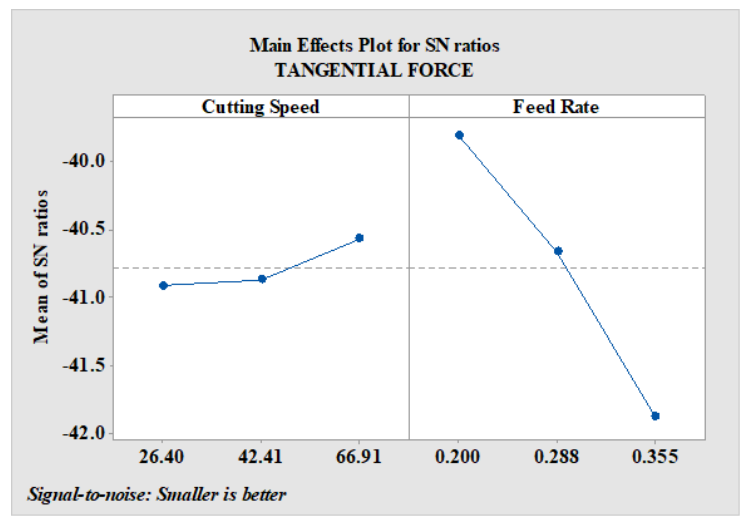

Fig. 20. Plots for $\mathrm{SN}$ ratio of $\mathrm{Al}-6061$ with $12 \% \mathrm{TiC}$

Fig. 16 to 20 shows the plots for SN ratio to decide the ideal set of machining parameters for this experimental design. The control factors used are cutting speed and feed rate. Table 7 shows the optimum parameters and their level, which gives the minimum cutting force [11]. Also, there are no conflicts happening in determining the various parameters while the standard parameters of the lowest response and uppermost $\mathrm{S} / \mathrm{N}$ ratio.

Table 7. Process parameters and their levels

\begin{tabular}{|c|c|l|}
\hline $\begin{array}{c}\text { Wt \% of TiC } \\
\text { in 6061 Al }\end{array}$ & $\begin{array}{c}\text { Optimum Cutting } \\
\text { Speed }\end{array}$ & Optimum Feed Rate \\
\hline 0 & Level $3(66.91 \mathrm{~m} / \mathrm{min})$ & Level $1(0.2 \mathrm{~m} / \mathrm{rev})$ \\
\hline 3 & Level $3(66.91 \mathrm{~m} / \mathrm{min})$ & Level $2(0.28 \mathrm{~m} / \mathrm{rev})$ \\
\hline 6 & Level $3(66.91 \mathrm{~m} / \mathrm{min})$ & Level $1(0.2 \mathrm{~m} / \mathrm{rev})$ \\
\hline 9 & Level $3(66.91 \mathrm{~m} / \mathrm{min})$ & Level $2(0.28 \mathrm{~m} / \mathrm{rev})$ \\
\hline 12 & Level $3(66.91 \mathrm{~m} / \mathrm{min})$ & Level $1(0.2 \mathrm{~m} / \mathrm{rev})$ \\
\hline
\end{tabular}

\subsection{Chip Formation}

Chip formation during machining was complemented by drastic plastic deformation at shear zone. TiC particulate added into Al alloy was initiated to decrease in ductility and 
produces a discontinuous type of chips. It is witnessed that the size of chip decreases on increasing the wt \% of TiC. Fig. 22 ( $a, b, \&$ c) shows the photographs of chip shapes produced by machining of cast composites. The size of the chips formed during machining of pure Al alloy is the chips produced by composites. Further the size of the chip formed during machining of $\mathrm{Al}$ reinforced with $3 \% \mathrm{TiC}$ is longer compared to $\mathrm{Al}$ reinforced with $12 \% \mathrm{TiC}$. This shows that reinforcement causes reduction in the size of chips.

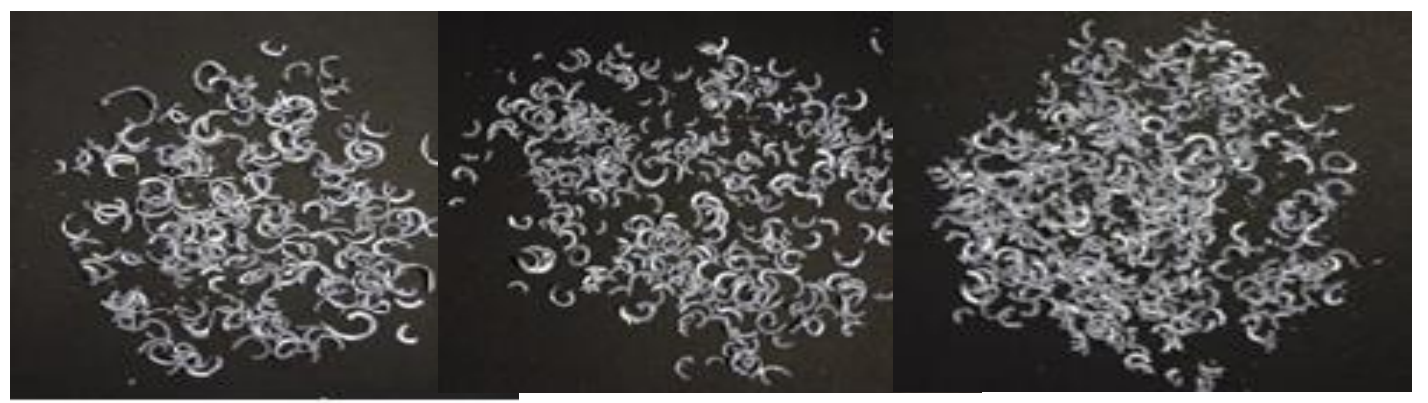

Fig. 22a. Shape of chips produced in Al alloy at 710 $\mathrm{rpm} \& 0.355 \mathrm{~mm} / \mathrm{rev}$.
Fig. 22b. Shape of chips produced in $\mathrm{Al} / 3 \% \mathrm{TiC} \mathrm{MMC}$ at $710 \mathrm{rpm} \& 0.355 \mathrm{~mm} / \mathrm{rev}$.
Fig. 24c. Shape of chips produced in $\mathrm{Al} / 12 \% \mathrm{TiC}$ $\mathrm{MMC}$ at $710 \mathrm{rpm} \& 0.355$ $\mathrm{mm} / \mathrm{rev}$.

\section{Conclusions}

- SEM micrograph shows uniform distribution of $\mathrm{TiC}$ particles with minimum agglomeration.

- EDX tests depicted the presence of TiC particles in the composites.

- It is observed that, the cutting force increases with the increase of feed rate for all the constant speeds and for all weight fractions. In some cases, the cutting force decreases with the increase of feed rate, probably due to the delamination of $\mathrm{TiC}$ particles from the matrix and due to slight reduction of brittleness of the composite because of increasing the temperature at higher feed rate.

- Cutting force decreases with the increase of cutting speed for all the constant feed rates and weight fractions. This may be due to reduction of friction at higher speeds.

- Hardness of the composite is increases as the wt. \% of TiC particles increases for all wt. $\%$ fractions.

- The optimum process parameters for achieving minimum cutting force for the material $0 \%, 6 \%$ and $12 \% \mathrm{TiC}$ composite at cutting speed of $66.92 \mathrm{~m} / \mathrm{min}$ and feed rate is 0.2 $\mathrm{mm} /$ rev compare with remaining Al- TiC composite materials.

\section{References}

1. Pushpendra kumar Jain, S C. Soni and Prashanth V.Baredar, Review on Machining of Aluminium Metal Matrix Composite, Material Science Research India,14(2),114-120, (2014).

2. V. Songemene, R. Khettabi, J. Kouam, A. Dejebra, Machining and Machinability of Aluminium Alloys, Intech, pp 378 - pp 400.

3. Rabindra Behra, S.Kayal, N.R. Mohanta, G.Sutradhar, Study on Machinability of Aluminium Silicon Carbide MMC, Indian Foundry Congress, (2013) 
4. Anand Kumar, M.M .Mahapatra, P.K.Jha, Effect of Machining Parameters on Cutting Force and Surface Roughness of In-Situ Al-4.5\%Cu/TiC MMC, Elsevier,Measurment,48,325-332, (2014)

5. Nassim Samer, Bruno Gardiola, Nikhil Karnatak, Olivier Martin, Microstructure and Mechanical Properties of Al-TiC by Reactive synthesis, Elsevier, Composites Part A,72,50-57 (2015)

6. Himanshu Kala, K.K.S Mer, Sandeep Kumar, a Review on Mechanical and Tribological Behaviour of Stir Cast AMMC, Elsevier, Procedia Materials Science, 6, 1951-1960, (2014).

7. Suraya Sulaiman, Shamsuddin Sulaiman, Noor Jaffer, Studies On Tensile Properties Of TiC Particulate Composites, Universiti of Malaysia Pahang, (2014)

8. P. Danashekaran, M. Ravishankar, S.Sathishkumar, N. Velavan, Tensile Test and Wear Behaviour of Titanium Carbide Reinforced With Al6063 MMC, International Research of Innovative Research in Science, (2015)

9. S. Venkatesan, M.Anthony Xavior, Comparative Analysis Of Aluminium MMC Reinforced With TiC And TiB2 Using Stir Casting Process, IJSRES,4, (2015)

10. C.R. Prakash Rao, Bhaghyashekar M.S, Narendra Vishwanath, Machining Behaviour of Al6061-Fly Ash Composites, Elsevier,5,1593-1602, (2014)

11. D. Saichaitanya Kishore, K. Prahalad Rao, A. Mahamani, Investigation of Cutting Force, Surface Roughness and Flank Wear in Turning of In-Situ Al6061-TiC MMC.Elsevier,6,1040-1050, (2014)

12. Dr. R.R Malagi, Rajesh BC, Factors Influencing In Turning And Development Of Software To Estimate Cutting Forces In Turning, IJEIT,2,37-43, (2012)

13. Dr. Thella Babu Rao, Theory of Metal Cutting and Machining Tools, GITAM University. 